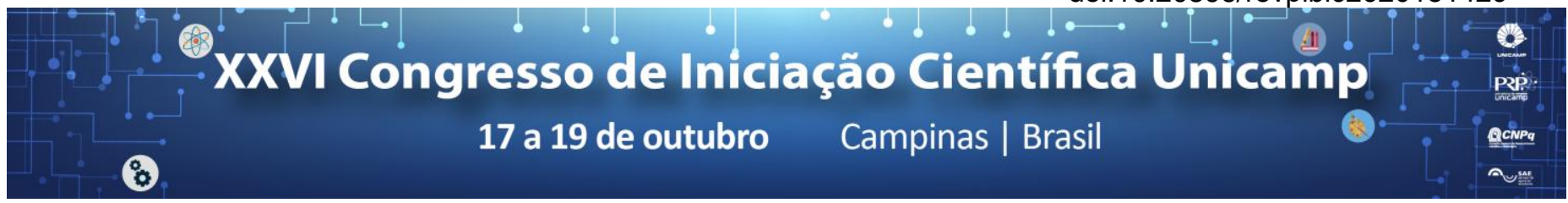

\title{
ESTUDO DA PRODUÇÃO E CARACTERIZAÇÃO DE ENZIMAS PARA APLICAÇÃO EM ALIMENTOS
}

\author{
Helen Aparecida da Silva Pinck*, , Laryssa Cristine Ribeiro dos Santos e Tamires Ramires Barbosa, Josinei \\ Magalhães de Freitas, Helia Harumi Sato
}

\section{Resumo}

O trabalho visou o estudo da produção de alfa-amilase por linhagens de Bacillus sp LBA para a aplicação na indústria de alimentos. Entre as 108 linhagens testadas as linhagens 03; 16; 25; 27; 68; 107; 108 e 113 produziram 44,0 U/mL; 35,1 U/mL; 38,2U/mL; 51,3 U/mL; 42,9 U/mL; 50,7 U/mL; 50,3 U/mL; e 43,0 U/mL de alfa-amilase, respectivamente. A alfa-amilase de Bacillus sp 107 apresentou atividade ótima em pH 6,5 e estabilidade na faixa de pH 5 a 10 após $24 \mathrm{~h}$ a 25ํ $\mathrm{C}$ e a alfa-amilase de Bacillus sp 108 apresentou atividade ótima em $\mathrm{pH} 7,0$ e 65ํㅡ e mostrou-se estável na faixa de pH 5 a 10 após $24 \mathrm{~h}$ a $25^{\circ} \mathrm{C}$.

Palavras-chave: Bacillus sp, alfa-amilase, produção de enzima.

\section{Introdução}

Enzimas são proteínas que catalisam ou aceleram as reações. Dentre as diversas enzimas, podemos destacar a alfa-amilase que hidrolisa as ligações alfa-1,4 glicosídicas do amido ao acaso liberando glicose, maltose, maltotriose, maltotetraose, oligossacarídeos e alfa-limite dextrina. A alfa-amilase é utilizada para hidrólise ou liquefação do amido e produção de maltodextrinas. A enzima pode ser utilizada em combinação com outras enzimas amilolíticas na produção de glicose e frutose. $\mathrm{O}$ presente trabalho visou o estudo da produção da alfaamilase por linhagens de Bacillus sp. e estudo de algumas características bioquímicas da enzima.

\section{Resultados e Discussão}

Entre as 108 linhagens de Bacillus sp testadas foram selecionadas 8 linhagens como melhores produtoras de alfa-amilase. No estudo da produção de alfa-amilase em meio de cultura composto de $1 \%$ de amido de batata; $0,2 \%$ de peptona; $1 \%$ de $\mathrm{KH}_{2} \mathrm{PO}_{4} ; 0,25 \%$ de $\mathrm{Na}_{2} \mathrm{HPO}_{4}$; $0,1 \%$ de $\mathrm{NaCl} ; 0,2 \%$ de $\left(\mathrm{NH}_{4}\right)_{2} \mathrm{SO}_{4} ; 0,005 \%$ de $\mathrm{CaCl}_{2}$, ajustado para $\mathrm{pH} 7,0$ (HASAN et al, 2017), em frascos Erlenmeyer incubados a $37^{\circ} \mathrm{C}$ por $48 \mathrm{~h}$ e $150 \mathrm{rpm}$ as linhagens de Bacillus sp 03; 16; 25; 27; 68; 107; 108 e 113 apresentaram 44,0 U/mL; 35,1 U/mL; 38,2U/mL; 51,3 $\mathrm{U} / \mathrm{mL} ; 42,9 \mathrm{U} / \mathrm{mL} ; 50,7 \mathrm{U} / \mathrm{mL} ; 50,3 \mathrm{U} / \mathrm{mL}$; e $43,0 \mathrm{U} / \mathrm{mL}$, de alfa-amilase respectivamente.

No estudo da produção de alfa-amilase em meio de cultura contendo amido de batata comercial e amido solúvel marca Synth foi obtido maior atividade de alfaamilase utilizando-se amido solúvel marca Synth. A alfaamilase da linhagem de Bacillus sp 107 apresentou atividade ótima em $\mathrm{pH} 6,5$ e pH de estabilidade na faixa de $\mathrm{pH} 5,0$ a 10,0 .

A alfa-amilase de Bacillus sp 108 apresentou atividade ótima em $\mathrm{pH} 7,0$ e $65^{\circ} \mathrm{C}$ e estabilidade na faixa de $\mathrm{pH} 5,0$ a 10,0 .

\section{Conclusões}

Entre as 108 linhagens de Bacillus sp testadas, as linhagens 03; 16; 25; 27; 68; 107; 108 e 113 apresentaram 44,0 U/mL; 35,1 U/mL; 38,2U/mL; $51,3 \mathrm{U} / \mathrm{mL} ; 42,9 \mathrm{U} / \mathrm{mL}$; $50,7 \mathrm{U} / \mathrm{mL} ; 50,3 \mathrm{U} / \mathrm{mL} ;$ e $43,0 \mathrm{U} / \mathrm{mL}$ de alfa-amilase respectivamente. A alfa-amilase da linhagem de Bacillus sp 107 apresentou atividade ótima em $\mathrm{pH}$ 6,5 e estabilidade na faixa de $\mathrm{pH} 5$ a 10 , enquanto que a linhagem de Bacillus sp 108 apresentou atividade ótima em $\mathrm{pH} 7,0$ a $65^{\circ} \mathrm{C}$ e estabilidade na faixa de $\mathrm{pH} 5$ a 10.

\section{Agradecimentos}

A PRP- UNICAMP; PIBIC-EM/CNPq pelas bolsas de estudo.

\section{Referências Bibliográficas}

1. OLIVEIRA, A.N.; OLIVEIRA, L.A.; ANDRADE, J. S.; CHAGAS JÚNIOR, A.F. Produção de amilase por rizóbios, usando farinha de pupunha como substrato. Ciência e Tecnologia de Alimentos. V. 27, p. 61-66, 2007.

2. HASAN, M.; MARZAN,L.W.; HOSNA, A.; KAKIM, AI., AZAD, A.K. Optimization of some fermentation conditions for the production of extracellular amylases by using Chryseobacterium and Bacillus isolates from organic kitchen wastes, Journal of Genetic Engineering and Biotechnology, v.15, n.1, p.59-68, 2017.

3. FIGUEIRA, J. A. Determinação e caracterização de amido e cana de açúcar e adequação da metodologia para determinação de alfa-amilase em açúcar bruto. Dissertação de mestrado - Faculdade de Engenharia de Alimentos - Unicamp 18/02/2009. 